\title{
It's the Little Things that Count...
}

\author{
Dr. Sara Adhitya and Prof. Nick Tyler \\ Universal Composition Laboratory, University College London, UK
}

\begin{abstract}
This paper will discuss the importance of detailed design decisions in the long term sustainability of any infrastructure system. It presents the concept of Universal Composition, first introduced by UCL's new Universal Composition Laboratory ('UCL-squared') and emerging from the need to design in space and time for multiple senses towards the creation of more accessible, understandable and meaningful environments. It thus presents infrastructure design from the point of view of human perception, and argues the need to design for the senses in order to encourage sustainable behaviours concerning human mobility, transport and locational choice.

After first explaining people-environment interactions, it discusses how the design of our urban infrastructure systems and environments can help stimulate our senses and thus behavioural change. Through two examples concerning bus stops implemented in London, it will explain how the role of both low and high tech technologies can help enhance interaction, improve accessibility and encourage usage. Thus, this paper aims to show that seemingly small details have a big role to play in the creation of infrastructure systems which enable, rather than inhibit, long term sustainable development.
\end{abstract}

Keywords: Urban Infrastructure Systems, Universal Composition, People-Environment Interactions, Multisensorial Design, Space-Time

\section{INTRODUCTION}

All too often, when thinking about infrastructure, people think about large systems - railways, bridges, communications networks, health systems and so on. However, it is useful to pause for a moment to think about the purpose of infrastructure. The word means "that which lies underneath and supports a structure" ${ }^{1}$ and in the context of interactions between infrastructure and people, this includes the support for the structure of society as well as support for structures such as buildings, transport or communications systems. According to Tyler, infrastructure has an important role to play in the improvement of quality of life and thus the achievement of societal wellbeing. In the search for societal wellbeing, Tyler $\left(2013^{2}, 2014^{3}\right)$ suggests that we should think of and design city systems according to the 5-city model, based on five basic principles: 1 . a city should be courteous; 2 . active and inclusive; 3 . felt as being owned by the public; 4. healthy; and 5. able to adapt to changing needs over time. Each of these 'cities' is described in terms of a person-

1 Oxford University Press (1989), Oxford English Dictionary

2 Tyler N. (2013) Future Cities: Meeting the Brundtland challenge. ISNGI Wollongong

3 Tyler N. (2014) A vision for cities: the 5-city model ARGnote 1(5) www.cege.ucl.ac.uk/arg/ARGnote.aspx 
environment context. That is, the city should be designed to: 1 . encourage people to show mutual respect for each other; 2. make activities accessible to everyone; 3. help make people feel safe; 4. contribute to positive health gain; and 5. help meet people's needs in the future. Thus in order to obtain societal wellbeing, infrastructure design must first address how individuals encounter infrastructure and the implications these encounters have for both the people and the infrastructure system itself. It is therefore incumbent upon designers to design these interactions between people and infrastructure. Thus this paper will discuss infrastructure in terms of people-environment interactions.

\section{PEOPLE-ENVIRONMENT INTERACTIONS}

With societal wellbeing being dependent on our people-environment interactions, in this section we explore what these interactions are. Three issues that need to be considered when considering the interface between people and the environment are: the way in which a person perceives the environment; the way the environment changes over time; and the extent of the environment that needs to be considered.

\section{Perception of 'Environment'}

It is important to realise that what is loosely called 'the environment' is something which is experienced by individuals in a way that is highly idiosyncratic. This is because of the way in which the human being responds to their immediate environment. Their responses are governed by the brain, but in particular by the preconscious mechanisms within the brain that determine the responses to environmental stimuli, and whether they are subconscious or conscious. To appreciate this, it is helpful to think about one sense, such as vision, as an example. Instead of thinking about vision as being active - "I look at the street" - we really should think of it as a data collector - "the street is showing me these features". Of the billions of stimuli being received by the brain in the form of bits of data, only a few reach the person's conscious state. ${ }^{4}$ The same is happening, in parallel, with our other senses such as hearing, touch, smell and taste. It is also important to note that there are many more senses than just these, including pain, balance, spatial perception, rhythm, colour, fear, fairness and so on are all crucial to a person's survival - making it too massive an operation for the brain to process consciously. 5,6 We understand our environments through sensorial interactions and thus the multisensorial design of our infrastructure systems can make them easier to perceive on a preconscious level, rendering them more intuitive, understandable, navigable and accessible.

\section{Temporal Environments}

The environment is in a state of constant and continuing change. Every time a person walks through a certain street or place, it will be different - there will be different colours, movements, sounds, images, lighting and so on. One of the main causes of this change is people. In an instant, 'other' people actually become part of the infrastructure with which one person interacts - they cluster around a sign or a shop window, move into and out of shops, move in and change between different directions and they stop. Yet there is a tendency to design the environment as though it were somehow permanent and unchanging. If we want to improve people-environment interactions, we need to explicitly incorporate these environmental changes in our design. In essence, we need to design in time as well as space.

\section{Personal versus Universal}

As the person is the unit of interaction, we have to start by ensuring that everyone is taken into consideration when designing the urban environment. Sensorial capabilities vary between people, and many people lack a sense, such as vision, or their senses can deteriorate over time. In order to be inclusive we need to consider combinations of senses in relation to our design. As these interactions occur between people and the environments they use, we also need to consider all elements of the environment so that it can offer as many possibilities for interaction with people as possible. While these interactions are generic and apply everywhere, how we design them in different places will need to consider a number of local factors, including spatial, cultural and climatic features so that the design will be appropriate in its intended location. Thus the 'personal' and the 'universal' are both essential in our concept of how to think about the urban realm.

\footnotetext{
4 Trans4mind, http://www.trans4mind.com/transformation/transform4.1.htm Accessed 28 May 2014

5 Ibid. Accessed 28 May 2014

6 Johnson K. (2009) The Element. Penguin, London, UK
} 


\section{Introducing 'Universal Composition'}

In order to develop a design approach which embraces all three of these characteristics, we have developed the concept of Universal Composition - the multisensorial design of the environment in space and time. It refers to the compositional processes by which more 'temporal' art forms such as music, poetry, or dance achieve their objective through the blend of different sensorial stimuli in space and time. This can be applied to 'static' art forms such as built form and hard transport infrastructure, which in effect are temporal in its composition of movement. It considers elements of the environment as a product-process pair, rather than either a product or a process. It is universal because it relates to everyone, everything, everywhere at every time. The Universal Composition Laboratory at University College London ( $\left.\mathrm{UCL}^{2}\right)$ is a new multidisciplinary design-research laboratory which studies and implements the principles of Universal Composition in all its projects, with the aim to improve societal wellbeing. ${ }^{7}$

One of the outcomes from the universal composition approach is that it needs to concentrate on the actual interaction between a person and their immediate environment - how they hear it, see it, feel it and so on - in space and time. This means that it is crucial to consider the small details of the environment, not only in the sense of the small elements of the system (e.g. a lamp pole or bus stop) but also the sensorial details of those elements (e.g. their colour, sound and feel). We argue that by paying greater attention to these small but numerous elements of the environmental infrastructure, great change in people-environment interactions can be achieved through their sheer number and far-reaching distribution. London, for example, has almost 20,000 bus stops and small changes to improve our interaction with them can thus yield a great difference in pedestrian/ passenger behaviour across the network, as well as affect other urban systems such as social and environmental. UCL ${ }^{2}$ argues that it is indeed the little things that count.

\section{COMPOSING FOR OUR SENSES}

Considering only the basic senses described above, the difference we can make to people's lives through the composition - i.e. multisensorial spatio-temporal design - of their microscale environments is clear. In the following sections we will investigate how we can redesign two simple activities which are key to any transport infrastructure system - walking and waiting - by applying the principles of universal composition.

\section{Composing for walking}

First we would like to highlight the role of infrastructure in designing 'speed', or what Adhitya refers to as the composition of urban rhythm. ${ }^{8}$ This relates strongly to Lefebvre's theory of Rhythmanalysis ${ }^{9}$ and the embodiment of environmental rhythms surrounding us which we measure against the metronome of our own internal bodies. According to Adhitya ${ }^{10}$, we should be composing these urban rhythms at the appropriate spatial scale for the speed at which they are travelled through. In order to compose this temporal movement, we must first design them at the appropriate spatial scale. By designing for the stimulus at a typical walking speed, we would make the environment more interesting, stimulating and enjoyable for people, whereas designing for a typical vehicular speed would yield environments that are rather boring for pedestrians. For example, the rhythm of activity provided in Cat Street (Figure 1) provides a level of stimulus that is inviting enough for people to be there. Grafton Way (Figure 2) and Paddington Basin (Figure 3) however, provide little stimulation and thus remain relatively empty passages through which people pass as quickly as possible. Thus, in order to improve people-environment engagement, we must design, or rather compose, places with the appropriate rhythm.

\section{Composing for waiting}

The act of waiting is another activity in which we often find ourselves obliged to partake. However, the design of our infrastructure means that this becomes, more often than not, a chore rather than a pleasurable activity. A simple design solution is to provide seating for people to rest themselves and their belongings. The physical design is easy enough - its form as well as the location of the seats. However, universal composition calls for the design of the

7 UCL, Universal Composition Laboratory, http://www.cege.ucl.ac.uk/arg/ucl-squared Accessed 28 May 2014

8 Adhitya S (2013) Sonifying Urban Rhythms - towards the spatio-temporal composition of the urban environment, Paris, Venice

9 Lefebvre (2004) Rhythmanalysis: Space, Time and Everyday Life, Continuum, London

10 Adhitya (2013) 
seating in a multisensorial, temporal way. The view from the seat should be considered, as well as its surrounding soundscape, lighting, and the available activities there - e.g. a book loan, coffee bar, etc. - that make sitting and waiting a pleasure rather than a chore. Figure 4 shows an example where the added height available from standing on the seat enabled people to enjoy watching a concert being given behind the bus stop even though the concert itself was hidden behind screens. Universal composition should encourage multiple uses over time.

\section{UNIVERSAL COMPOSITION IN LONDON}

$\mathrm{UCL}^{2}$ is currently involved in a number of experiments in the public domain where multisensorial design in space and time can be explored. The two examples discussed in this paper both concern bus stops - a result of responding to an opportunity rather than being the only possibility. However, bus stops are an important 'phase change' element of our infrastructure system, being the point at which we transform from pedestrian (walking) to passenger (waiting), and should be composed with care.

\section{Interactive bus stops}

The first example consists of two interactive bus stop installations in Regent Street in London on 22 June 2014. On this day, the street was closed to traffic for the 'Day of the Bus'11, and Transport for London granted permission to $\mathrm{UCL}^{2}$, in collaboration with Goldsmiths University, to transform 2 bus stops. Through a series of multisensorial, low and high tech interventions, we sought to change people's perception of the bus stop from something where they are discouraged to linger, to a place where it is great to be.

The first bus stop was transformed into a digital musical instrument which could be played by the public ${ }^{12}$. The seating was fitted with pressure sensors which were linked to digital synthesizers, creating a series of 'musical chairs'. New signage advertising the bus routes was created, which could be played like percussion instruments.

The second bus stop was used as a physical foil, in which the public, through a series of practical visual activities, could change the 'image' of a bus stop and thus the perception of its function(s) ${ }^{13}$. The public was invited to decorate it as well as arrange different types of furniture and other objects to create the sense of, for example, a 'living room' or an 'office space'. The objective was to position the passer-by to view this everyday infrastructure object as an important compositional element of their urban environment which can change over time.

Through these interventions, we hoped to use universal composition to change the perception of a bus stop from being an everyday urban object to being a pleasurable experience in the urban realm, and thus open up the possibilities of what it could be. This event was a starting point for further multisensorial design interventions to other bus stops in London, which we are currently developing.

\section{'Edible' bus stops}

The concept of 'Edible bus stops' started life as a guerrilla gardening initiative in South London (Figure $5^{14}$ ) when a group of local residents decided to take over a piece of derelict ground near a bus stop to create a garden and thus improve the environment of the bus stop. $\mathrm{UCL}^{2}$ intends to apply this idea to central London by constructing an 'edible bus stop' at a central London bus stop located in a busy corridor with limited pedestrian space and surrounded by buildings on either side of the street ${ }^{15}$ (its current appearance can be seen in Figure 6 . The plan is to construct a 50m-long garden using plants which are suitable for the area and have the best impact on local wildlife. We are investigating plants that generate better health benefits, through the improvement of the air quality, as well as being aromatic and colourful, and possibly even edible. In addition, we are working with Transport for London to determine what can be done with the current shelter, which is more of an obstacle to pedestrians along the narrow pathway. We hope to recompose the shelter into a new organic design, such that the seating is integrated alongside the garden and the shelter provided by the plants from the garden. Based on the previous experience of interactive

\footnotetext{
11 Transport for London. http://www.tfl.gov.uk/campaign/our-events Accessed 28 May 2014

12 designed by Sara Adhitya, UCL², Music technology: Matthias Moos, Alexander Bigden, Goldsmiths, University of London

13 designed by Liliana Ortega, $\mathrm{UCL}^{2}$

14 http://www.theediblebusstop.org/ Accessed 28 May 2014
} 


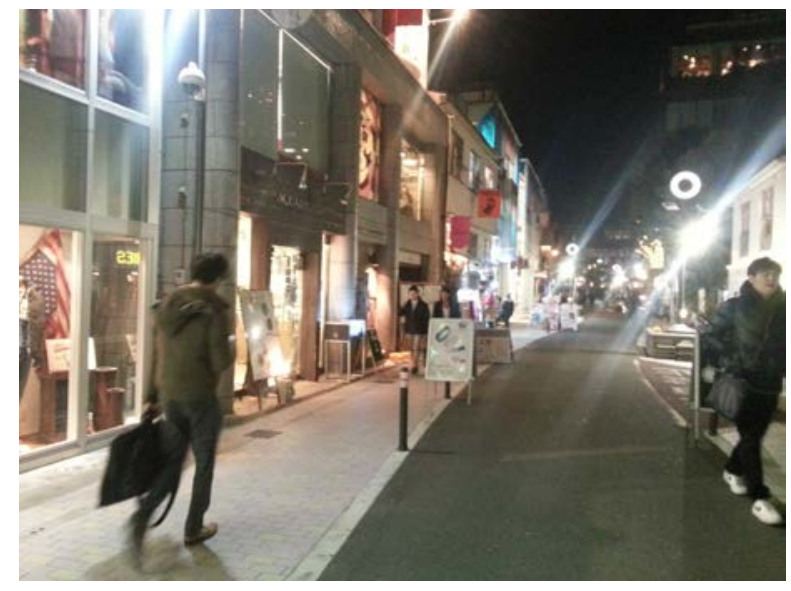

Figure 1 Cat Street, Tokyo, Japan

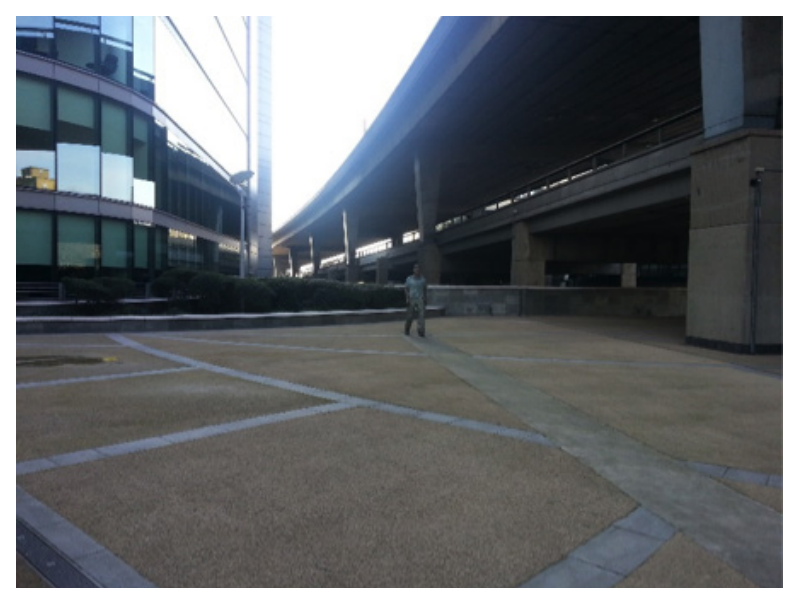

Figure 3 Paddington Basin, London

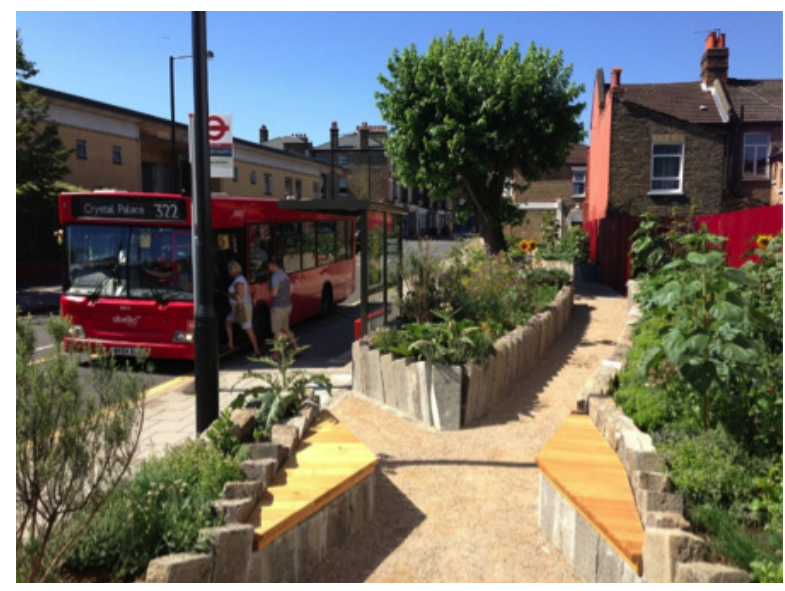

Figure 5 The Edible Bus Stop in Lewisham, London

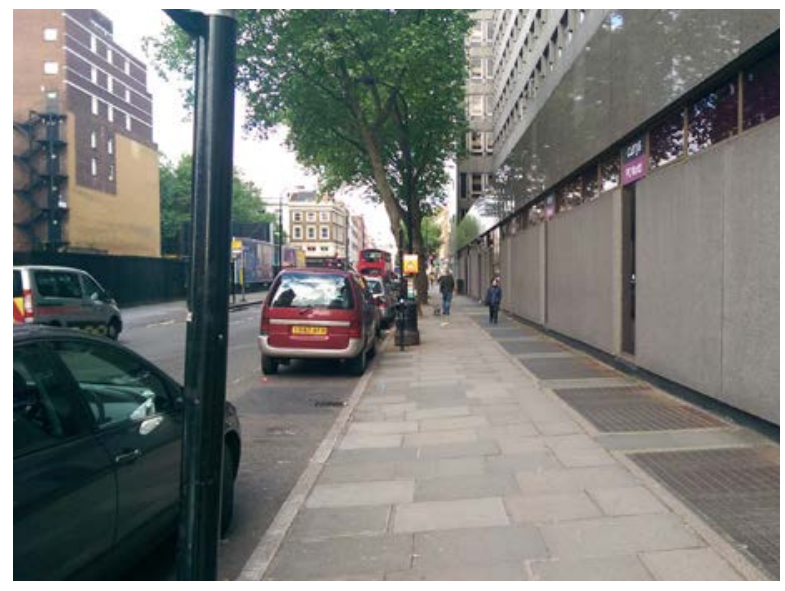

Figure 2 Grafton Way, London, UK

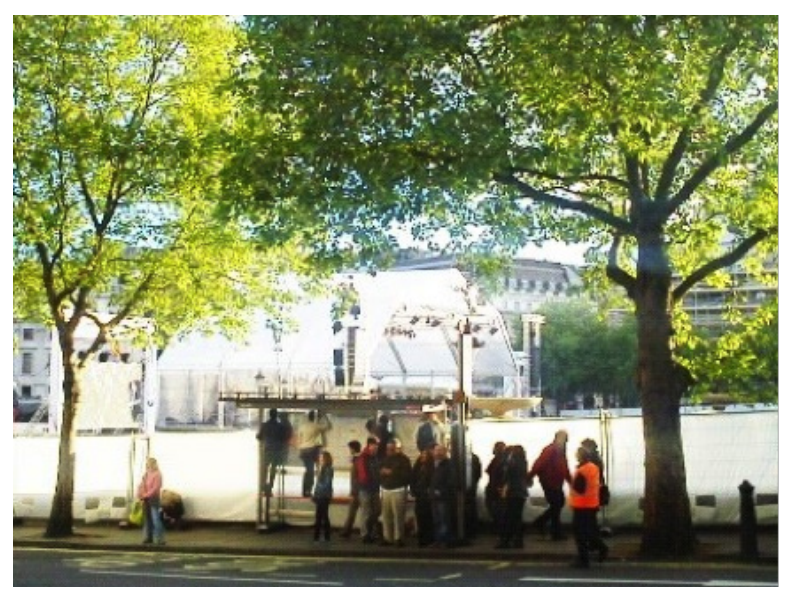

Figure 4 Bus stop assisting a concert in Trafalgar Square, London

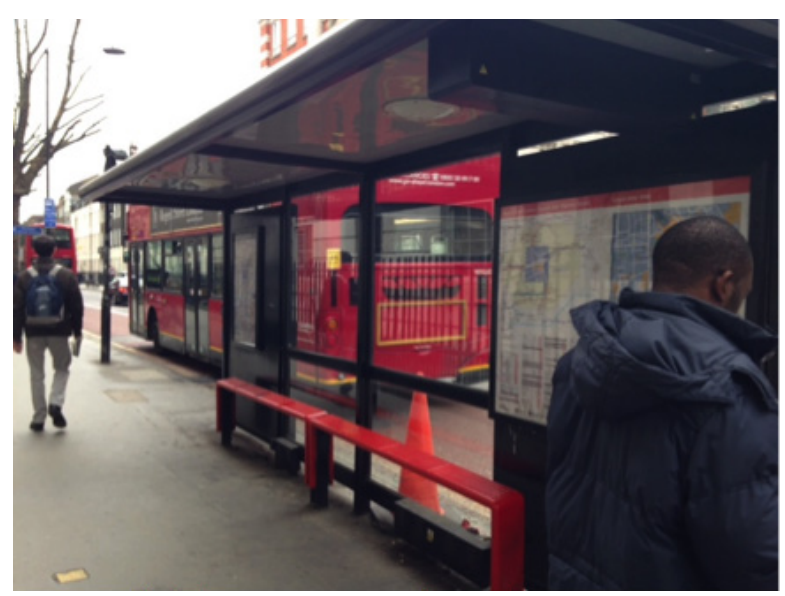

Figure 6 Site of a future 'edible bus stop', Gower Street, London 
bus stops described above, we also hope to integrate audio and visual technology to aid interaction with and communication of the system. The bus stop will thus become a dynamic element in space and time - it will look and smell different according to the seasons, as well as itself contribute to different microclimatic conditions. Furthermore, it will compose new people-environment interactions through encouraged interactions with it, and it is anticipated lead to different behavioural outcomes. This project is currently in the stages of planning approval.

\section{CONCLUSIONS}

In order for infrastructure to support the improvement in societal wellbeing, it is necessary to consider our interactions with it from the perspective of the sensing individual. In order to be used, infrastructure should be considered as a provider of pleasurable experience, rather than something that is imposed. At $\mathrm{UCL}^{2}$, we believe that positive change starts from positive experiences, and that the dynamic, multisensorial design of our people-environment interactions is the key. Our interactive bus stops are an example of how rethinking the design of one element in a big network can in fact help change the perception of a whole infrastructure system and assist in large-scale behavioural change. By applying the principles of universal composition to these seemingly small but numerous infrastructure elements, $\mathrm{UCL}^{2}$ aims to improve the perception of our next generation infrastructure systems and promote sustainable and positive change. 